\title{
Recuperação da desnutrição em ratos mediante rações adicionadas ou não de suplemento alimentar e de vitaminas e minerais durante o período de crescimento ${ }^{1}$
}

\section{Recovery from malnutrition in rats with or without the addition of dietary food supplements, vitamins and minerals during the growth period}

Maria Angélica GUZMÁN-SILVA²

Aline Rabello WANDERLEY ${ }^{3}$

Viviane Miguel MACÊDO ${ }^{3}$

Gilson Teles BOAVENTURA 4

\section{R E S U M O}

\section{Objetivos}

O propósito deste estudo foi analisar experimentalmente a eficiência da suplementação alimentar da dieta do M unicípio de Quissamã, RJ, em recuperar a desnutrição durante o período de crescimento.

\section{Métodos}

Foram utilizados 42 Rattus norvegicus, desmamados ao 260 dia e induzidos à desnutrição por 21 dias (ração hipoprotéica $2 \%$, ad libitum). Os animais foram distribuídos em sete grupos, alimentados com suas respectivas dietas, todas isoprotéicas $(10 \%)$ e isoenergéticas $(350 \mathrm{Kcal} / 100 \mathrm{~g})$. Foi registrado o peso dos animais e, após 0 sacrifício, foram coletados e pesados fígado, rins, baço e intestino.

\section{Resultados}

O ganho ponderal médio no $28^{\circ}$ dia do controle suplemento alimentar $(75,33 \mathrm{~g})$ foi significativamente inferior aos demais grupos, e o do controle suplemento alimentar e vitaminas+minerais foi o mais elevado $(213,17)$.

\footnotetext{
${ }^{1}$ Apoio: PIBIC/CNPq e FAPERJ (Processo no E-26/170.613/2000 - APQ1).

2 Departamento de Patologia, Universidade Federal Fluminense. Rua Marquês de Paraná, 303, 24030-210, Centro, Niterói, RJ. Brasil. Correspondência para/Correspondence to: M.A. GUZMÁN-SILVA. E-mail: mptmags@vm.uff.br

${ }^{3}$ Bolsistas, Laboratório de Nutrição Experimental, Faculdade de Nutrição, Universidade Federal Fluminense, Brasil.

${ }^{4}$ Departamento de Nutrição e Dietética, Universidade Federal Fluminense, Brasil.
} 
Quase todos os grupos diferenciaram-se estatisticamente no peso médio de fígado, rins e baço; os órgãos do controle suplemento alimentar apresentaram o menor peso (respectivamente $3,34 \mathrm{~g} ; 0,97 \mathrm{~g} ; 0,24 \mathrm{~g}$ ) sendo significativamente inferior aos demais grupos. 0 controle suplemento alimentar e vitaminas+minerais apresentou o maior peso médio do fígado $(13,85 \mathrm{~g})$. 0 Controle vitaminas+minerais apresentou o maior peso médio dos rins $(1,88 \mathrm{~g})$ e do baço $(0,87 \mathrm{~g})$. 0 número de placas de Peyer/animal variou de nove a treze, sem diferenças entre os grupos; o tamanho das placas de Peyer do controle suplemento alimentar $(2,6 \mathrm{~mm})$ foi significativamente inferior aos demais grupos. 0 Quissamã suplemento alimentar apresentou as maiores placas de Peyer $(4,4 \mathrm{~mm})$. 0 controle suplemento alimentar apresentou sempre valores inferiores para todos os parâmetros estudados comparativamente, já que não foram adicionados à sua ração vitaminas e minerais.

\section{Conclusão}

A dieta de Quissamã, RJ experimentalmente alcança as necessidades mínimas para promover a recuperação da desnutrição, sendo desnecessária a adição de vitaminas e minerais e/ou suplemento alimentar.

Termos de indexação: desnutrição protéico-energética, suplemento alimentar, peso corporal, ratos, vitaminas na dieta.

\section{A B S T R A C T}

\section{Objective}

The objective of this study was to analyze dietary food supplementation efficiency in the municipal district of Quissamã, RJ, for recovery from malnutrition during the growth period.

\section{Methods}

We used 42 Rattus norvegicus, weaned on the 26th day and induced to malnutrition for 21 days (low protein diet $2 \%$, ad libitum). The animals were divided into 7 groups and fed their respective diets, all of them isoproteic $(10 \%)$ and isocaloric $(350 \mathrm{Kcal} / 100 \mathrm{~g})$. Their body weight was registered and liver, kidneys, spleen and intestines were collected and weighed after the animals were sacrificed.

\section{Results}

On the 28th day, the mean weight gain $(75.33 \mathrm{~g})$ in the supplementary food control group was significantly inferior to the other groups, and the mean weight gain of the supplementary food and vitamins + minerals control group was the highest $(213.17 \mathrm{~g})$. Almost all the groups showed statistical differences for the mean weight of the liver, kidneys and spleen; in the supplementary food control group these organs presented the lowest weight (respectively $3.34 \mathrm{~g} ; 0.97 \mathrm{~g} ; 0.24 \mathrm{~g}$ ), being significantly inferior to the other groups. The supplementary food and vitamins + minerals control group presented the highest mean liver weight $(13.85 \mathrm{~g})$, as well as the highest kidneys $(1.88 \mathrm{~g})$ and spleen mean weight $(0.87 \mathrm{~g})$. The number of Peyer patches/animal varied from 9 to 13 , without differences among the groups; the size of the Peyer patches $(2.6 \mathrm{~mm})$ for the supplementary food control group was significantly smaller than in the other groups. The Quissamã food supplement presented the largest Peyer patches $(4.4 \mathrm{~mm})$. The food supplement control group presented lower values for all of the studied comparative parameters, since no dietary vitamins and minerals were added.

\section{Conclusion}

The Quissamã, RJ diet reaches the minimal needs to promote recovery from malnutrition, rendering unnecessary the addition of vitamins and mineral and/or food supplementation.

Index terms: protein-energy malnutrition, food supplement, body weight, rats, dietary vitamins. 


\section{N T R O D U Ç Ã O}

A desnutrição protéico-energética é, de longa data, considerada um problema social, sendo inclusive apontada como um marcador de pobreza ${ }^{1}$, medida também através de habitações precárias, baixos salários, analfabetismo, desemprego ou empregos mal remunerados ${ }^{2}$.

A desnutrição também está relacionada a doenças infecto-parasitárias ${ }^{3}$, sendo seu processo de recuperação multifatorial, exigindo uma grande mobilização de recursos e de pessoal. Para isso, foram criados vários programas de combate à desnutrição, entre eles podemos destacar a "Alimentação Alternativa" (Multimistura ou Suplemento Alimentar) da Pastoral da Criança ${ }^{4}$.

A Pastoral da Criança vem introduzindo 0 programa de Multimistura (M M) em todo o Brasil, inclusive no município de Quissamã, localizado na Região Leste Fluminense do Estado do Rio de Janeiro. Este programa foi iniciado em 1994 e, desde então, o Laboratório de Nutrição Experimental (LABNE) da Faculdade de Nutrição da Universidade Federal Fluminense vem estudando os efeitos da utilização da MM na recuperação da desnutrição experimental ${ }^{5}$. A M M é atualmente denominada Suplemento Alimentar (SA) devido a mudanças na sua composição, que era originariamente de farelos, folhas e sementes e, atualmente, inclui alguns produtos industrializados.

$\mathrm{Na}$ desnutrição protéico-energética, 0 organismo responde às restrições de forma singular, manifestando fraqueza, caquexia, retardo do crescimento, não conseguindo adaptar-se à deficiência protéica que é acompanhada por edema, perda da massa muscular, fígado graxo (esteatose), dermatose, diminuição da resposta imune e debilidade geral ${ }^{6}$. As alterações anatômicas na deficiência protéico-energética podem ser generalizadas, como hipoplasia e atrofia dos tecidos ${ }^{7}$ e, conseqüentemente, diminuição do tamanho corporal e dos órgãos ${ }^{8,9}$. Portanto, a análise do peso de diversos órgãos nos permite verificar o comprometimento de sua massa e estrutura, em detrimento da desnutrição e deficiência mineral e vitamínica.

Se o SA alcançar seu objetivo de suplementar vitaminas e minerais, pode facilitar a recuperação da desnutrição. Temos como objetivo estudar a influência da adição do SA em grupos de ratos previamente desnutridos, alimentados com dietas que provêem aporte protéico capaz de recuperar a desnutrição, adicionadas ou não de vitaminas e minerais. Nesses animais, previamente desnutridos e recuperados durante o período de crescimento, analisamos a variação de peso corporal e os seguintes órgãos, fígado, rins, baço e intestino. A análise do peso dos órgãos sólidos e do número e tamanho das placas de Peyer nos permite verificar o grau de recuperação de sua massa e estrutura.

\section{MATERIALE MÉTODOS}

Foram utilizados 42 Rattus norvegicus, raça W istar, variedade Albinos, machos, desmamados no 26 - dia de vida, provenientes do LABNE do Departamento de Nutrição e Dietética da Universidade Federal Fluminense. A pós o período de desmame os animais foram submetidos à desnutrição através de ração hipoprotéica com $2 \%$ de caseína durante 21 dias. Os animais foram mantidos no Biotério, confinados em gaiolas individuais de polipropileno, em ambiente com temperatura constante $\left(24^{\circ} \mathrm{C} \pm 2^{\circ} \mathrm{O} C\right)$ e iluminação adequada (ciclo claro e escuro de 12 em 12 horas).

Os animais foram sorteados aleatoriamente e divididos em sete grupos experimentais, com seis ratos cada, recebendo as rações durante 28 dias (Tabela 1).

Foram registrados os pesos dos animais dos dias zero, sete, quatorze, vinte e um e vinte e oito. A média foi utilizada como medida de tendência central de cada grupo, em cada período de registro. A curva de variação do peso teve início no momento zero, ou seja, no primeiro dia da recuperação da desnutrição previamente induzida. 
Depois de sacrificados por deslocamento cervical, os animais foram laparatomizados e foram coletados fígados, rins, baços e intestinos, sendo lavados rapidamente em solução salina (soro fisiológico). Assim, todos os órgãos sólidos foram pesados; a média foi utilizada como medida de tendência central do grupo e o desvio-padrão como medida de dispersão. As placas de Peyer foram contadas e de cada grupo foram mensuradas 50 placas, sendo a média utilizada como medida de tendência central do grupo.
A dieta de Quissamã foi elaborada com base no inquérito recordatório realizado pela equipe de profissionais da Secretaria Municipal de Saúde da Prefeitura de Quissamã, RJ, com os pais de 27 crianças inscritas e participantes do projeto do Perfil Alimentar das crianças do Subprograma da M ultimistura, conforme descrito por Boaventura et al. ${ }^{5}$. A partir deste inquérito foram determinados os alimentos habitualmente consumidos pelas crianças e que foi denominada Dieta de Quissamã. Esses alimentos, após a

Tabela 1. Grupos experimentais e composição das rações.

\begin{tabular}{|c|c|c|c|c|}
\hline \multirow[b]{2}{*}{ Grupo } & \multicolumn{2}{|c|}{ Dieta protéica $(10 \%)$} & \multirow{2}{*}{$\begin{array}{l}\text { Suplemento } \\
\text { Alimentar }\end{array}$} & \multirow{2}{*}{$\begin{array}{l}\text { Vitaminas e M inerais } \\
\qquad(A I N-93 G)\end{array}$} \\
\hline & Caseína & Quissamã & & \\
\hline Controle + vm (Cvm) & Sim & Não & Não & Sim \\
\hline Controle + SA (CSA) & $\mathrm{Sim}$ & Não & Sim & Não \\
\hline Controle + SA + vm (CSAvm) & $\mathrm{Sim}$ & Não & Sim & Sim \\
\hline Quissamã (Q) & Não & Sim & Não & Não \\
\hline Quissamã + vm (Qvm) & Não & Sim & Não & Sim \\
\hline Quissamã + SA (QSA) & Não & Sim & $\mathrm{Sim}$ & Não \\
\hline Quissamã + SA + vm (QSAvm) & Não & Sim & $\mathrm{Sim}$ & Sim \\
\hline
\end{tabular}

Tabela 2. Composição em $100 \mathrm{~g}$ das rações utilizadas durante o ensaio.

\begin{tabular}{lccccccc}
\hline $\begin{array}{l}\text { Ração } \\
\text { Componentes }(\mathrm{g})\end{array}$ & $\begin{array}{c}\text { Controle } \\
+\mathrm{vm}\end{array}$ & $\begin{array}{c}\text { Controle } \\
+\mathrm{SA}\end{array}$ & $\begin{array}{c}\text { Controle } \\
+ \text { SA }+\mathrm{vm}\end{array}$ & $\begin{array}{c}\text { Quissamã } \\
\text { Quissamã } \\
+ \text { vm }\end{array}$ & $\begin{array}{c}\text { Quissamã } \\
+ \text { SA }\end{array}$ & $\begin{array}{c}\text { Quissamã } \\
+ \text { SA + vm }\end{array}$ \\
\hline Caseína $^{1}$ & 13,49 & 13,49 & 13,49 & - & - & - & - \\
Dieta de Quissamãa $^{2}$ & - & - & - & 76,68 & 76,68 & 76,68 & 76,68 \\
Amido $^{3}$ & 60,16 & 62,86 & 58,36 & 17,07 & 12,52 & 15,27 & 10,67 \\
Mistura de Minerais $^{4}$ & 3,50 & - & 3,50 & - & 3,50 & - & 3,50 \\
Mistura de Vitaminas $^{5}$ & 1,00 & - & 1,00 & - & 1,00 & - & 1,00 \\
Óleo $^{6}$ & 6,30 & 6,00 & 6,00 & 0,70 & 0,75 & 0,40 & 0,50 \\
Celulose $^{7}$ & 5,00 & 5,00 & 5,00 & 5,00 & 5,00 & 5,00 & 5,00 \\
Colina $^{8}$ & 0,25 & 0,25 & 0,25 & 0,25 & 0,25 & 0,25 & 0,25 \\
L-cistina $^{8}$ & 0,30 & 0,30 & 0,30 & 0,30 & 0,30 & 0,30 & 0,30 \\
Suplemento Alimentar $^{9}$ & - & 2,10 & 2,10 & - & - & 2,10 & 2,10 \\
Açúcar $^{10}$ & 10,00 & 10,00 & 10,00 & - & - & - & - \\
\hline Total & 100,00 & 100,00 & 100,00 & 100,00 & 100,00 & 100,00 & 100,00 \\
\hline
\end{tabular}

1 = Kauffmann Co; 2 = Elaborada segundo o Inquérito da Secretaria M unicipal de Saúde do M unicípio de Quissamã, RJ*; 3 = Maisena ${ }^{\circledR}$; 4 = Preparada segundo AIN-93 (elaborada no LABNE/UFF); 5 = Preparada segundo a AIN-93 (cedida pela Roche); $6=$ Liza $\AA$; $7=$ Microcel $\AA$, Blanver Ltda.; 8 = Vetec; 9 = Alimentos alternativos preparados e consumidos no Município de Quissamã**; $10=$ Dolce.

(*) Constituintes da Dieta de Quissamã em 100g: Ovo 5,90; Carne moída 4,72; Carne de porco 1,18; Pescada 1,65; Carne de frango 5,90; Arroz 25,94; Neston 2,36; Couve 8,25; Batata 4,13; Mandioca 1,77; Feijão 12,03; Açúcar 4,13; Manteiga 0,24; Leite 4,72; Banana 7,08; Laranja 8,25; Nescau 1,53; Óleo 0,24; Total $100 \mathrm{~g}$. Fonte: Boaventura et al. ${ }^{5}$.

${ }^{(* *)}$ Composição do Suplemento Alimentar em 100g: Aveia 16,66; Farinha de trigo 16,66; Fubá 20,00; Gergelim 6,66; Gérmen de trigo 6,66; Leite em pó 13,33; Extrato de soja 11,66; Semente de abóbora 3,33; Semente de girassol 3,33; Casca de ovo 1,66; Total 100g; Fonte: Secretaria Municipal de Saúde da Prefeitura de Quissamã, RJ ${ }^{5}$. 
cocção, foram desidratados a $60^{\circ} \mathrm{C}$, em estufa ventilada (Fabre - Primer), por 24 horas. A seguir, os alimentos dessecados foram triturados e homogeneizados em batedeira industrial (Hobarte $\left.{ }^{\circledR}\right)$.

As amostras do SA foram coletadas junto à Secretaria M unicipal de Saúde da Prefeitura de Quissamã, RJ (Tabela 2). Nota-se a presença de componentes conven-cionais em sua composição tornando inviável a denominação de M ultimistura.

As rações utilizadas foram confeccionadas no LABNE, sendo preparadas com $10 \%$ de proteína, adicionadas das misturas de minerais e de vitaminas segundo as normas do Commitee on Laboratory Animal Diets de $1979^{10}$, modificadas segundo as recomendações da AIN-93 ${ }^{11} \mathrm{e}$ adicionadas de $2,1 \%$ do SA. Os percentuais relativos às quantidades de vitaminas e minerais, e de $\mathrm{SA}$, no preparo de $100 \mathrm{~g}$ de cada ração, bem como os valores de macronutrientes presentes nas dietas são referidos na Tabela 2.

Os testes estatísticos foram aplicados mediante o programa SPSS 9.0. Com a finalidade de comparar os resultados obtidos para cada aspecto analisado em todos os grupos foi aplicado o teste não paramétrico de análise de variância de Kruskal-Wallis H. A seguir, havendo encontrado diferença estatística ao comparar todos os grupos, foi aplicado o teste não paramétrico de Mann Whitney $U$ para cada aspecto analisado. Foram considerados como significativos os valores com $p \leq 0,05$.

\section{RES U LTA D O S}

0 início da recuperação dos ratos, com suas respectivas rações, deu-se no dia zero e seu término no $28^{\circ}$ dia, sendo que os valores de peso no momento zero foram homogêneos, variando de $51,67 \mathrm{~g}$ a $55,5 \mathrm{~g}$. Ao final do experimento observou-se que os animais dos grupos Cvm e QSAvm apresentaram valores aproximados de peso corporal e os dos demais grupos, valores distintos entre si (Figura 1). A curva ponderal do grupo CSA alcançou valores bem inferiores aos demais, apresentando valores que não se alteraram ao longo dos 28 dias e o peso desses animais foi significativamente inferior ao de todos os outros grupos $(p<0,01)$. Ainda, houve diferença estatística entre o peso dos animais do grupo CSAvm e os grupos Q, Qvm, CSA e Cvm $(p<0,05)$.

0 peso dos fígados do CSA foi significativamente inferior ao de todos os outros grupos $(p<0,01)$. Por outro lado, o peso dos fígados do CSAvm foi significativamente superior ao de todos os outros grupos ( $p<0,01)$, exceto em relação ao Cvm. Por sua vez, o peso do fígado do Cvm foi significativamente superior ao de Q, Qvm e QSA $(p<0,05)$. Finalmente, o peso dos fígados do grupo QSAvm foi significativamente superior ao de Q e Qvm $(p<0,05)$, e o peso dos fígados do QSA foi significativamente superior ao do Qvm $(p<0,05)$ (Tabela 3).

Tabela 3. Peso médio $(\mathrm{g})$ e desvio-padrão de órgãos de ratos desnutridos submetidos à recuperação com diversas dietas.

\begin{tabular}{|c|c|c|c|c|}
\hline Grupo & Fígado & Rins & & Saço \\
\hline Cvm $(n=5)$ & $12,08 \pm 1,72^{3}$ & $1,88 \pm 0,08^{6}$ & 0,87 & $\pm 0,45$ \\
\hline $\operatorname{CSA}(n=6)$ & $3,34 \pm 0,45^{1}$ & $0,97 \pm 0,06^{1}$ & 0,24 & $\pm 0,05^{1}$ \\
\hline CSAvm $(n=6)$ & $13,85 \pm 1,42^{2}$ & $1,80 \pm 0,16^{7}$ & 0,58 & $\pm 0,12$ \\
\hline$Q(n=6)$ & $8,52 \pm 1,03$ & $1,67 \pm 0,13^{7}$ & 0,47 & $\pm 0,09$ \\
\hline Qvm $(n=6)$ & $8,36 \pm 0,98$ & $1,52 \pm 0,07$ & 0,56 & $\pm 0,09$ \\
\hline QSA $(n=6)$ & $10,08 \pm 1,16^{5}$ & $1,72 \pm 0,11^{7}$ & 0,70 & $\pm 0,07^{9}$ \\
\hline QSAvm $(n=6)$ & $10,27 \pm 1,20^{4}$ & $1,64 \pm 0,13$ & 0,64 & $\pm 0,09^{8}$ \\
\hline
\end{tabular}

Teste de Mann-Whitney; $1=p<0,01$ vs. todos os grupos; $2=p<0,01$ vs. todos os grupos, exceto Cvm; $3=p<0,05$ vs. $Q, Q v m$ e QSA; $4=p<0,05$ vs. $Q$ e $Q v m ; 5=p<0,05$ vs. Qvm; $6=p<0,05$ vs. todos os grupos, exceto CSAvm; $7=p<0,05$ vs. $Q v m ; 8=p<0,05$ vs. $Q ; 9=p<0,05$ vs. CSAvm, Q e Qvm. 
$64 \mid$ M.A. GUZMÁN-SILVA et al.

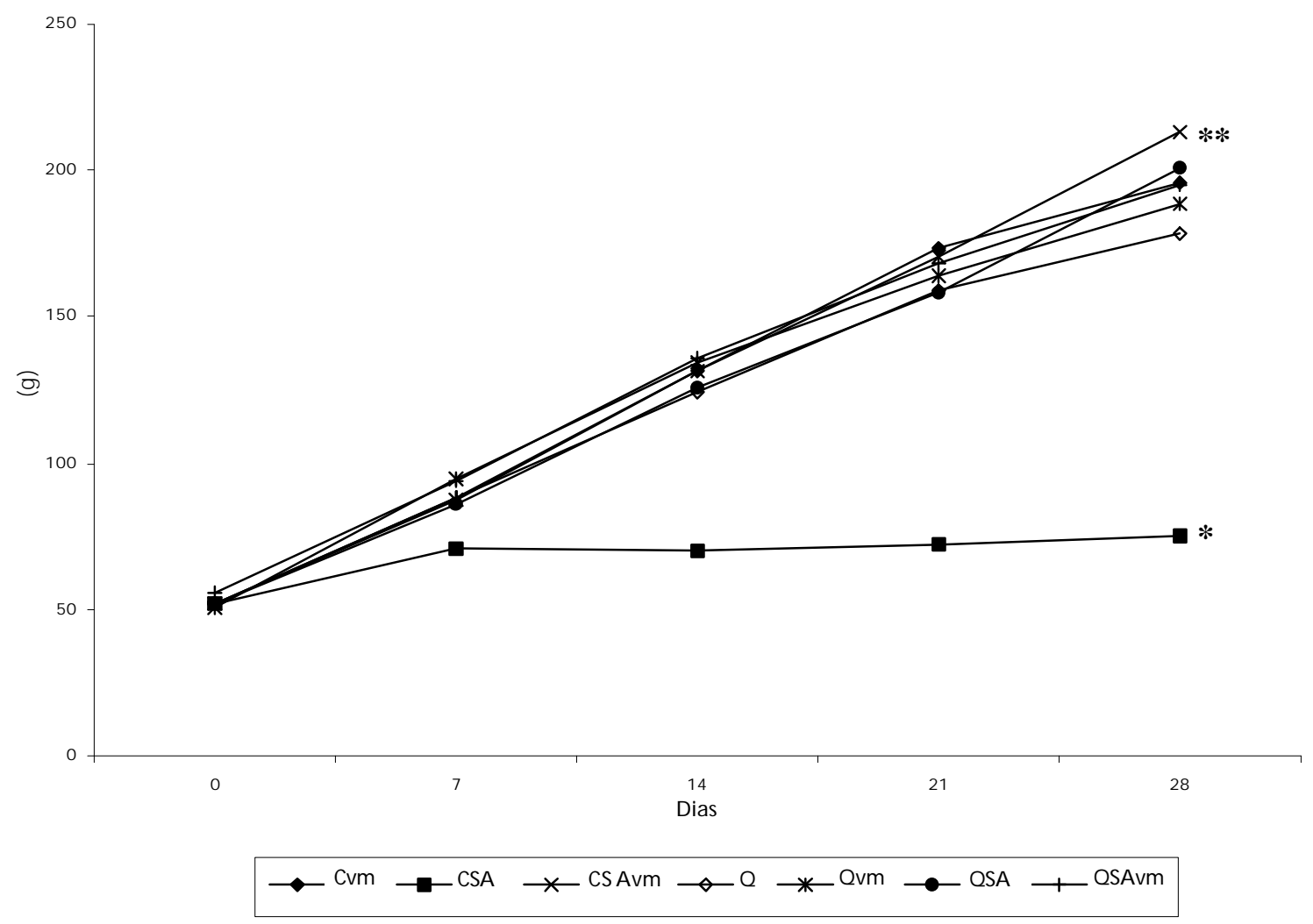

Nota: * $p<0,01$ vs. todos os grupos; ** $p<0,05$ vs. Q, Qvm, QSA e Cvm; teste de Mann-Whitney.

Figura 1. Variação de peso de ratos desnutridos submetidos à recuperação mediante diversas dietas.

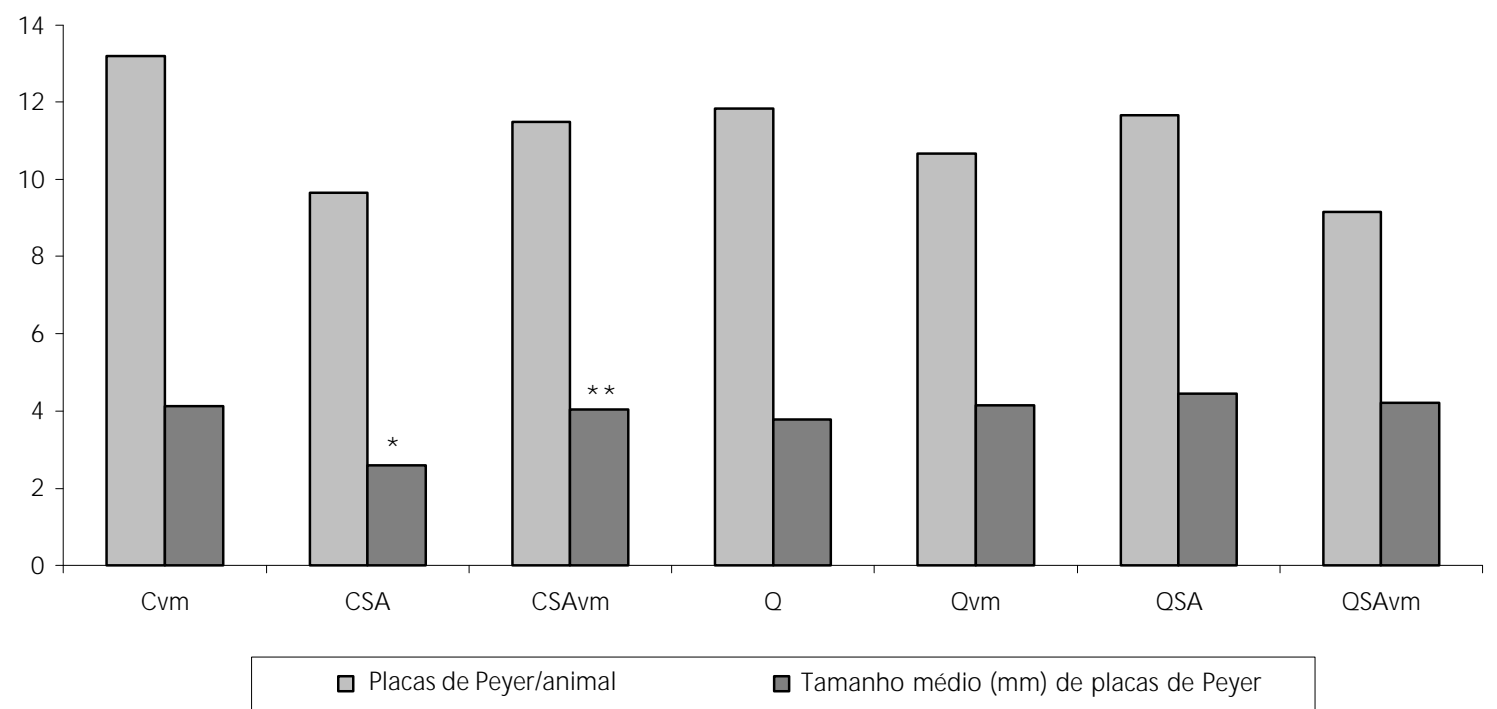

Nota: $* p<0,01$ vs. todos os grupos; ${ }^{* *} p<0,05$ vs. QSA; teste de Mann-Whitney

Figura 2. Placas de Peyer de ratos desnutridos e recuperados mediante diversas dietas. 
0 peso dos rins do grupo CSA foi significativamente inferior ao de todos os outros grupos $(p<0,01)$. Já o peso dos rins do Cvm foi significativamente superior ao de todos os outros grupos $(p<0,05)$, exceto ao do CSAvm. Por sua vez, o peso dos rins de CSAvm, QSA e $Q$ foi significativamente superior ao do Qvm $(p<0,05)$. Em relação ao peso dos baços do CSA este foi significativamente inferior ao de todos os outros grupos $(p<0,01)$. Por outro lado, o peso dos baços de Cvm e QSAvm foi significativamente superior ao do $Q(p<0,05)$. Por último, o peso dos baços do QSA foi significativamente superior ao de CSAvm, Qvm e Q $(p<0,05)$ (Tabela 3).

Observou-se que a média de placas de Peyer/animal variou de 9 no QSAvm a 13 no Cvm (Figura 2). Os outros grupos apresentaram valores intermediários, sem haver grandes diferenças entre todos os grupos. Já o tamanho das placas de Peyer do CSA $(2,6 \mathrm{~mm})$ foi significativamente inferior ao de todos os outros grupos $(p<0,01)$, e as placas de Peyer do QSA $(4,4 \mathrm{~mm})$ foram significativamente superiores às do $Q(3,8 \mathrm{~mm})(p<0,05)$. Os outros grupos não apresentaram diferenças marcantes entre si, variando o tamanho das placas de Peyer entre $4,1 \mathrm{~mm}$ e $4,2 \mathrm{~mm}$.

\section{I S C U S S Ã 0}

O período entre a gestação e os cinco anos de idade é, do ponto de vista nutricional, segundo Lajolo \& Tirapeguí, o mais vulnerável segmento do ciclo de vida do homem. Daí a importância do estudo da desnutrição na fase de crescimento. Boza et al. ${ }^{12}$ citam que a desnutrição pela restrição dietética e fome severa produz uma série de mudanças metabólicas, que levam à redução do peso corporal, depressão da imunocompetência e função alterada do sistema digestivo, particularmente do fígado e do intestino delgado. Entretanto, animais desnutridos durante o período pré e pós-natal ao serem alimentados com dieta adequada nutricionalmente, rapidamente melhoram seu peso, no entanto, o peso alcançado após o perío do de recuperação de 30 dias $^{9}$ e 120 dias $^{13}$ é inferior ao dos animais controle.

Para dados de peso corporal, Guerra \& Peters $^{14}$ mostram a evolução do peso a cada 10 dias a partir do $30^{\circ}$ dia. No $50^{\circ}$ dia, os ratos machos apresentaram, em média, $113,79 \mathrm{~g}$ e no $80^{\circ} \mathrm{dia}$, o peso médio era de $194,47 \mathrm{~g}$. Foi considerado os pesos relatados por Guerra \& Peters ${ }^{14}$, do $30^{\circ}$ ao $80^{\circ}$, como parâmetro de normalidade, para animais não submetidos à desnutrição. Da mesma forma Hossne et al. ${ }^{15}$ relatam peso corporal médio de $206 \mathrm{~g}$, variando entre $180 \mathrm{~g}$ e $240 \mathrm{~g}$ para ratos machos normais com 70 dias de idade.

Embora os animais desse experimento tenham sido submetidos à desnutrição, no $75^{\circ}$ dia alcançaram pesos semelhantes aos apresentados por Guerra \& Peters ${ }^{14}$ e por Hossne et al. ${ }^{15}$. Esses pesos variaram de $178,17 \mathrm{~g}$ a $213,17 \mathrm{~g}$, com exceção do CSA que apresentou valor bem inferior de peso médio, sendo de 70,67g. Para valores de variação de peso, Veloso ${ }^{16}$ encontrou $121,16 \mathrm{~g}$ para o seu grupo Controle e M ultimistura (adicionado de vitaminas e minerais, segundo AIN-93). Assim pode-se comparar esse grupo com o CSA vm, onde foi encontrado valor próximo, sendo este de $161,5 \mathrm{~g}$ para variação de peso em 28 dias.

Constatou-se então que o maior ganho ponderal dos animais do CSAvm não foi estatisticamente diferente de QSAvm e do QSA. Pode-se, então, especular que a dieta de Quissamã contém algumas vitaminas e minerais em quantidades suficientes, daí os resultados similares em QSAvm e QSA. Além disso, a dieta de Quissamã, sem qualquer suplementação, parece ser suficiente para a recuperação do peso corporal, mas não da mesma forma que nesses grupos, considerando que o SA desempenha algum papel no ganho ponderal quando associado, em particular, à dieta de Quissamã.

Nesta pesquisa, no protocolo experimental, o grupo Cvm representa o controle de todo o experimento, pois uma dieta composta apenas por caseína, sem a adição de vitaminas e minerais levaria a morte dos animais. Quando é feita a 
suplementação da caseína exclusivamente com Suplemento A limentar tem-se o menor ganho de peso dos animais (Figura 1). Já a dieta de Quissamã, sem qualquer suplemento, contém vitaminas e minerais pelos próprios componentes dos alimentos (Tabela 2).

Sabe-se que, para a manutenção da homeostase do fígado, o organismo prioriza a perda da massa hepática com quadros de hipoplasia e atrofia, em vez de alterar sua função. Como cita Parra et al. ${ }^{17}$, a desnutrição associa-se à perda de massa hepática para garantir a disponibilidade de energia a órgãos importantes, como coração e cérebro. Para Boza et al. ${ }^{12}$ a restrição alimentar pode produzir uma redução de $30 \%$ no peso do fígado e que essa redução hepática é proporcionalmente maior quando comparada à perda de massa corporal que apresentou um decréscimo de $14,5 \%$ do seu peso total. Segundo Hossne et al. ${ }^{15}$, aos 30 dias de idade, em condições normais de alimentação, 0 fígado de ratos machos evidencia peso médio de $2,80 \mathrm{~g}$, os rins apresentam peso médio de $0,71 \mathrm{~g} \mathrm{e}$ o baço pesa em média 0,33g. Nessa fase animais dessa pesquisa já estavam inseridos no processo de desnutrição prévia daí a importância do período de recuperação, a fim de proporcionar substrato ao organismo para o crescimento do organismo como um todo.

Foi observado ainda que, depois da recuperação efetuada durante o período de crescimento, todos os animais alcançaram valores satisfatórios para a recuperação do peso do fígado e dos rins, exceto o grupo CSA $(3,34 \mathrm{~g}$ e $0,97 \mathrm{~g}$, respectivamente). Os ratos de CSAvm $(13,85 \mathrm{~g} \mathrm{e}$ $1,80 \mathrm{~g}$, respectivamente) e de Cvm $(12,08 \mathrm{~g}$ e $1,88 \mathrm{~g}$, respectivamente) destacaram-se por apresentarem os maiores valores, sem diferença estatística entre si, o que nos mostra que a adição do SA não incrementou o ganho de peso desses órgãos nos grupos controle. Os valores de referência utilizados são os descritos por Hossne et al. ${ }^{15}$, em ratos machos normais aos 70 dias de idade, sendo em média $8,57 \mathrm{~g}$ para o fígado e $1,64 \mathrm{~g}$ para os rins. Assim, a desnutrição protéica pode ser revertida rapidamente através do aumento da ingestão protéica, ocorrendo aumento do peso corporal e do desenvolvimento do fígado ${ }^{18}$.

Já segundo Zeman ${ }^{19}$, a privação de proteína pré-natal tem efeitos em longo prazo, ou até permanentes, sobre a morfologia do rim no rato jovem e afeta a função renal de forma persistente, pelo menos até o fim do desmame. Considerando que o rim do rato é relativamente imaturo quando do nascimento, é provável que o aumento da alimentação pós-natal tenha um efeito mais benéfico e rápido nestes tecidos em desenvolvimento.

Analisando os grupos baseados na dieta de Quissamã, a adição de SA parece ter proporcionado algum efeito no desenvolvimento hepático, já que o QSA vm $(10,27 \mathrm{~g})$ foi significativamente superior ao Q $(8,52 \mathrm{~g})$ e Qvm $(8,36 \mathrm{~g})$, e por sua vez o QSA $(10,08 \mathrm{~g})$ foi significativamente superior ao Qvm. Em relação ao desenvolvimento dos rins, o papel do SA não é tão evidente, pois QSAvm $(1,64 \mathrm{~g}), \mathrm{QSA}(1,72 \mathrm{~g})$ e Q $(1,67 \mathrm{~g})$ foram grupos com resultados similares entre si, porém só o grupo QSA e o Q foram significativamente superiores ao grupo Qvm $(1,52 \mathrm{~g})$.

A desnutrição induzida, com dieta pobre em proteína $(2 \%$ ), por um período de seis a oito semanas tem como resultado a depleção linfo-histiocitária, que é representada morfologicamente por depleção linfóide esplênica, atrofia das placas de Peyer e diminuição das células de Küpffer no fígado ${ }^{8}$. Esses achados são atribuídos à carência protéica, porquanto os animais controle desse experimento, mesmo com restrição energética, não apresentaram as alterações do tecido linfóide ${ }^{8}$. 0 estudo de Koster $\&$ Pierce $^{20}$ indica que a privação de proteína em ratos, durante dois meses, prejudica o desenvolvimento de linfócitos esplênicos supressores, entretanto, esse efeito é reversível após a realimentação, recuperando-se a resposta imune supressora do baço.

Com relação ao peso do baço, novamente o uso do SA associado à dieta de Quissamã parece ter contribuído para melhor recuperação desse 
órgão, pois QSA $(0,70 \mathrm{~g})$ foi estatisticamente superior a Q $(0,47 \mathrm{~g})$ e Qvm $(0,56 \mathrm{~g})$. 0 resultado de QSA, por ter sido também estatisticamente superior a CSA $(0,24 \mathrm{~g})$ e CSAvm $(0,58 \mathrm{~g})$, nos indica que a dieta de Quissamã comparada com a dieta de caseína, quando associada ao SA, determina melhor desenvolvimento esplênico. Este fato talvez possa ser explicado pelo fato da dieta de Quissamã ter maior diversidade na sua composição protéica.

Entretanto, a participação de vitaminas e minerais no desenvolvimento esplênico não pode ser esquecida, pois com base nos resultados apresentados verificou-se que Cvm $(0,87 \mathrm{~g})$ e QSAvm $(0,64 \mathrm{~g})$ foram estatisticamente superiores a CSA e Q e, por outro lado, foram similares a todos os grupos que incluíam vitaminas e minerais na ração ingerida. Novamente foi utilizado como valor padrão o peso médio do baço de $0,56 \mathrm{~g}$, descrito por Hossne et al. (1986/1987) ${ }^{15}$ aos 70 dias em ratos machos normais.

Na literatura, poucos estudos ${ }^{3}$ examinaram os efeitos da desnutrição na resposta imune no anfitrião parasita-infectado, e muito menos consideraram os eventos que acontecem em nível intestinal onde a absorção de nutrientes acontece, os parasitas intestinais residem, e o tecido linfóide associado ao intestino representam um papel importante dirigindo ambas as respostas imunes, local e sistêmica. A proximadamente 18 placas de Peyer podem ser identificadas ao longo do jejuno distal e íleo do intestino delgado de ratos adultos ${ }^{21}$. Nesse experimento, novamente o Cvm teve o melhor índice de recuperação, no que se refere ao número de placas de Peyer/animal, 13, aproximando-se do número referido para ratos adultos.

0 estudo de Flo et al. ${ }^{22}$ indica que a desnutrição, em ratos, durante 0 aleitamento provoca alterações em linfócitos B e T, e produz um déficit na indução das respostas imunes primárias e secundárias no Gut Associated Lymphoid Tissue que se inverte depois de três semanas de realimentação. Da mesma forma, a deficiência severa de proteína ao desmame, conduz à presença nas placas de Peyer de células B muito imaturas. Nestes ratos severamente privados de proteína a realimentação protéica durante nove e vinte e um dias, reinicia o processo de diferenciação linfóide ${ }^{23}, 0$ qual se estende pelo menos até 060 o dia ${ }^{24}$.

Considerando o tamanho das placas de Peyer, todos os grupos, exceto o CSA, recuperaram o desenvolvimento deste tecido linfóide de forma equivalente. No grupo QSA as placas de Peyer foram significativamente mais desenvolvidas que as do Q, o que novamente sugere alguma participação do SA na recuperação do tecido linfóide, particularmente quando associado à dieta de Quissamã.

\section{O N C L U S Ã O}

A recuperação da desnutrição foi satisfatória para todos os grupos experimentais, salvo para o CSA, pois a adição do SA à dieta que tinha como fonte protéica a caseína, proteína de alto valor biológico, sem a adição de vitaminas e minerais (AIN-93) não teve nenhum efeito benéfico. Contudo, quando a adição do SA foi efetuada nos grupos que tinham como base protéica à dieta de Quissamã, os resultados foram favoráveis.

A dieta de Quissamã, RJ, por si só alcança as necessidades mínimas para promover a recuperação da desnutrição, em termos do peso corporal e dos órgãos selecionados, sendo desnecessária a adição de vitaminas e minerais e/ou SA. Depreende-se assim que a problemática do município de Quissamã, RJ é o acesso aos alimentos em termos quantitativos e não qualitativos.

\section{REFERÊ N C I A S}

1. Issler RM S, Giugliani ERJ, Kreutz GT, Meneses CF, Justo EB, Kreutz VM, et al. Poverty levels and children's health status: study of risk factors in an 
urban population of low socioeconomic level. Rev Saúde Pública 1996; 30(6):506-11.

2. Azeredo VB, Carmo M GT, Boaventura GT, Dias M M, Lobo FP. M ultimistura: uma alternativa alimentar. Rio de Janeiro: Independente; 1999. 79p.

3. Scott ME, Koski KG. Zinc deficiency impairs immune responses against parasitic nematode infections at intestinal and systemic sites. J Nutr 2000; 130(5 Suppl):1412S-20S.

4. Pastoral da Criança (Brasil) [online] 2001 [citado 11 ago 2001]; Disponível em: http://www.rebidia. org.br/pastoral/rede11.html

5. Boaventura GT, Chiappini CCJ, Fernandes NRA, Oliveira EM. Avaliação da qualidade protéica de uma dieta estabelecida em Quissamã, Rio de Janeiro, adicionada ou não de multimistura e de pó de folha de mandioca. Rev Nutr 2000; 13(3):201-9.

6. Lajolo FM, Tirapegui J. Proteínas e aminoácidos. In: Dutra de Oliveira JE, Marchini SJ. Ciências Nutricionais. São Paulo: Sarvier; 1998. p.61-4.

7. Robbins SL, Cotran RS, Kumar V. Distúrbios nutricionais. In: Robbins SL, Cotran RS, Kumar V. Patologia estrutural e funcional. Rio de Janeiro: Interamericana; 1986. p.390.

8. Madi K, Campos SD. Desnutrição experimental: resultados anátomo-patológicos e bioquímicos da administração de dietas hipoprotéicas a ratos albinos jovens. Memórias do Instituto Oswaldo Cruz 1975; 73(3):153-81.

9. Nunes M L, Batista BB, M icheli F, Batistella V. Effects of early malnutrition and nutritional rehabilitation in rats. J Ped (Rio de Janeiro) 2002; 78(1):39-44.

10. Commitee on Laboratory Animal Diets / Assembly of Life Sciences. National Research Council. Control of diet in laboratory animal experimentation. Nutr Abst Rev 1979; 40:413-9.

11. Reeves PG, Nielsen FH Jr., Fahey GC. AIN-93 Purified diets for laboratory rodents: Final report of the American Institute of Nutrition ad hoc writing committee on the reformulation of the AIN-76A rodent diet. J Nutr 1993; 123:1939-51.
12. Boza JJ, Moënnoz D, Vuichoud J, Jarret AR, Gaudard-de-Weck D, Fritsché $R$, et al. Food deprivation and refeeding influence growth, nutrient retention and functional recovery of rats. J Nutr 1999; 129:1340-6.

13. Campos DG, Madi K. Studies on pre- and post-natal malnutrition in albino rats. Partial ponderal and biochemic recuperation. Rev Bras Pesq Med Biol 1975; 8(3-4):301-6.

14. Guerra MA, Peters VM. Morfometria de ratos Wistar: peso e medidas corporais. Rev Ciênc Bioméd 1995; 15:65-74.

15. Hossne WS, Spadella CT, Bacchi CE. Estudo biométrico de comprimento, peso corpóreo e peso de órgãos em animais de experimentação biomédica. Rev Ciênc Bioméd 1986/87; 7/8:1-19.

16. Veloso RV. Recuperação do estado nutricional de ratos desnutridos: avaliação do emprego de uma multimistura de alimentos não convencionais [dissertação]. Cuiabá: Instituto de Saúde Coletiva da Universidade Federal de Mato Grosso; 1998.

17. Parra MO, Hernandez-Blasquez FJ, Souza e Silva RAP, Silva JRMC, Peduto L, Soares MM, et al. Reduction of liver mass due to malnutrition in rats. Correlation with emaciation of animals and size of organs not inserted in the portal system. São Paulo Med 1995; 113(3):903-9.

18. Qu Z, Ling PR, Tahan SR, Sierra P, Onderdonk AB, Bistrian BR. Protein and lipid refeeding changes protein metabolism and colonic but not small intestinal morphology in protein-depleted rats. J Nutr 1996; 126(4):906-12.

19. Zeman FJ. The effect of prenatal protein-calorie malnutrition on kidney development in the rat. Progr Clin Biol Res 1983; 140:309-38.

20. Koster F, Pierce NF. Effect of protein deprivation on immunoregulatory cells in the rat mucosal immune response. Clin Exp Immunol 1985; 60(1):217-24.

21. Bivin WS, Crawford MP, Brewer NR. Morphophysiology. In: Baker HJ, Lindsey JR, Weisbroth SH, editors. The laboratory rat. Biology and diseases. New York: Academic Press; 1979. v.1, p.79. 
22. Flo J, Elias F, Benedetti R, Massouh E. Reversible effects on $B$ and $T$ cells of the gut-associated lymphoid tissues in rats malnourished during suckling: impaired induction of the immune response to intra-Peyer patches immunization with cholera toxin. Clin Immunol Immunopathol 1996; 80(2):147-54.

23. Roux ME, Lopez MC, Melton E, Slobodianik NH, Gonzalez Ariki S, Garcia P. The lymphoid system and protein deficiency. Differentiation in the thymus and Peyer's patches. Med (Buenos Aires) 1989; 49(2):162-5.

24. Lopez MC, Roux ME. Impaired differentiation of Ig A-B cell precursors in the Peyer's patches of protein depleted rats. Develop Comparative Immunol 1989; 13(3):253-62.

Recebido para publicação em 17 de outubro de 2002 e aceito em 28 de abril de 2003. 
